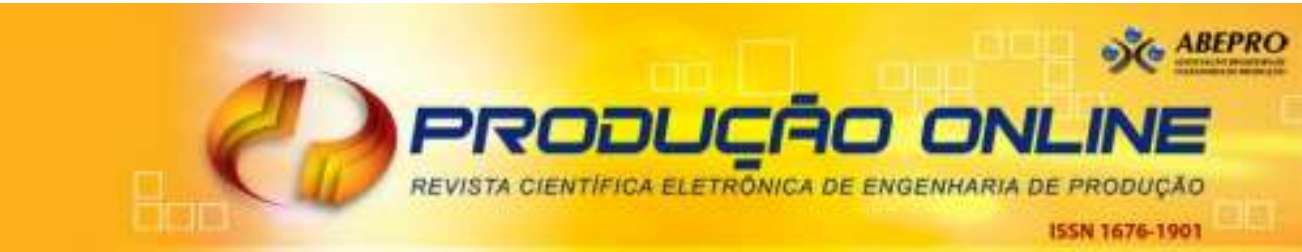

\title{
A INFLUÊNCIA DA GESTÃO DA CAPACIDADE NA DETERMINAÇÃO DO CUSTO UNITÁRIO DE PRODUÇÃO: UM ESTUDO DE CASO EM UMA EMPRESA DE EMBALAGENS PLÁSTICAS FLEXÍVEIS
}

\author{
THE INFLUENCE OF CAPACITY MANAGEMENT ON THE UNIT \\ COST OF PRODUCTION: A CASE STUDY IN A FLEXIBLE PLASTIC \\ PACKAGING COMPANY
}

\author{
Tálita Floriano Goulart da Silva* E-mail: talitafloriano@gmail.com \\ Maria Silene Alexandre Leite* E-mail: leite@ct.ufpb.br \\ *Universidade Federal da Paraíba (UFPB), João Pessoa, PB
}

\begin{abstract}
Resumo: Este artigo apresenta a relação entre a gestão da capacidade e a gestão de custos, na determinação do custo unitário de fabricação de uma empresa de embalagens plásticas flexíveis. $O$ objetivo foi mostrar como a utilização da capacidade efetiva diminui o custo unitário de fabricação. Para isto, foram seguidas tais etapas: 1) Conhecimento e análise do processo produtivo e o PPCP; 2 ) Coleta de Dados; 3) Aplicação do Método de Custeio Centro de Custos; 4) Verificação da relação entre a Gestão de Capacidade e Gestão de Custos. De posse dos relatórios contábeis da empresa estudada, observações diretas e entrevistas, pôde-se obter os seguintes resultados: conhecimento do processo produtivo e o funcionamento do PPCP, mensuração do custo de cada etapa do processo produtivo e o custo unitário de fabricação de cada produto. Posteriormente, comparou-se o custo unitário de fabricação de cada produto utilizando a capacidade efetiva com a capacidade média atual da empresa. Os resultados mostraram que os custos unitários diminuem com a utilização da capacidade efetiva, aumentando também a margem de cada produto, mesmo com a diminuição do preço de venda, estabelecendo desta forma um círculo virtuoso: utilização da capacidade efetiva, diminuição do custo unitário de fabricação, preços mais competitivos e aumento no número de pedidos.
\end{abstract}

Palavras-chave: Custos. Capacidade. PPCP. Centro de Custos. Embalagens.

Abstract: This article presents the relationship between capacity management and cost management in determining the unit cost. The objective was to show how the use of effective capacity decreases the unit cost of manufacturing. For this, follow these steps: 1) Knowledge and analysis of production process and PPPC; 2) Data Collection; 3) Application of the Method Cost Center; 4)Verification of the relationship between the Capacity Management and Cost Management. Through the company's accounting reports, observations and interviews, the following results was possible: knowledge of the production process and functioning of PPCP, measuring the cost of each step of the production process and the unit cost of each product. Subsequently, we compared the unit cost using the effective capacity and normal capacity. The results showed that the unit costs decrease with the use of effective capacity, while increasing the margin for each product, even with the lower sale price, thus establishing a virtuous circle: effective capacity utilization, reduced unit cost, most competitive prices and increase in the number of requests.

Keywords: Cost. Capacity. PPPC. Costs Center. Packaging.

Revista Produção Online, Florianópolis, SC, v.13, n. 3, p. 915-944, jul./set. 2013. 


\section{ASPECTOS INTRODUTÓRIOS}

Para obter informações acerca da contabilidade de custos é necessário apurar os dados com segurança e mensurá-los de forma mais fiel à realidade, para que a análise dos custos seja feita de forma coerente, e desta forma auxilie o processo de gestão da empresa (FREIRES, 2011; REIS, 2008).

Paralelamente a esta exigência, Nyhuins e Pereira Filho (2002) afirmam que o mercado exige um tempo mais curto de entrega e por isso, as empresas precisam de uma melhoria contínua na gestão da capacidade. Ainda segundo a fonte citada, antes a capacidade de entrega era equilibrada utilizando os estoques, porém, com as condições atuais, o aumento da variedade de produtos e a demanda flutuante, exigem novos e aprimorados recursos para o Planejamento, Programação e Controle da Produção (PPCP).

Para Dutra e Erdman (2007), o PPCP representa o eixo operacional de uma organização, sendo a estratégia de uma empresa construída com base nesta atividade. Para os autores citados, sua eventual deficiência projeta-se de forma imediata na qualidade do bem, na falta de confiabilidade de informações, em um pior aproveitamento dos recursos de produção, no descumprimento de prazos, no gerenciamento dos insumos, dentre outros aspectos. Assim, o PPCP é sensível aos acontecimentos ocorridos em seu ambiente externo.

Através da gestão do PPCP, aliado ao gerenciamento dos custos de fabricação pode-se reconhecer os produtos mais rentáveis, assim como a capacidade e eficiência dos processos, que por sua vez, estão intimamente ligadas com os custos dos produtos.

Pode-se estabelecer uma relação entre custo e capacidade, conforme afirma Moreira (2008), operar com uma capacidade diferente das necessidades de mercado irá aumentar inutilmente os custos operacionais. Neste raciocínio, Sabbadini et al. (2006) afirmam que no cenário atual é fundamental o ajuste da capacidade à demanda, identificando os recursos onde a alteração irá gerar o maior benefício, aumentando assim os lucros.

Para auxiliar a comparação dos custos com a capacidade na empresa estudada foi selecionado um método de custeio que apresenta características 
compatíveis com a estrutura e organização que a empresa dispõe atualmente, fato que facilita a utilização posterior do método para o controle de custos e despesas. $O$ método Centro de Custos satisfaz as necessidades da empresa em termos gerenciais, além de possibilitar o conhecimento do custo por quilo de produto. $A$ partir das constatações expostas estabelece-se o problema de pesquisa: verificar qual a influência da gestão da capacidade no custo unitário dos produtos de uma empresa de embalagens plásticas flexíveis.

\section{BASE CONCEITUAL}

Este tópico tem como objetivo discutir sobre planejamento, programação e controle da produção, gestão da capacidade e por fim, o método de custeio utilizado neste trabalho.

\subsection{Planejamento, Programação e Controle da Produção (PPCP)}

De acordo com Tubino (2009), o PPCP é responsável pela coordenação e aplicação dos recursos produtivos de forma a atender da melhor maneira possível aos planos estabelecidos nos níveis estratégicos, táticos e operacionais. Para Bikfalvi et al. (2010) um dos problemas essenciais do PPCP é a disponibilidade de entrega, nível de estoque e utilização dos recursos de produção. Ainda de acordo com os autores, a capacidade de se adaptar aos requisitos de mudança do cliente é uma importância crescente no campo da gestão industrial. Portanto, para evitar diferenças entre as exigências do cliente e as restrições dos recursos produtivos, o PPCP deve definir corretamente seu planejamento de longo prazo.

Os planos estratégicos definem qual o rumo que a empresa pretende seguir em longo prazo. Corrêa et al. (2007) afirmam que o planejamento da capacidade de longo prazo visa antecipar necessidades de capacidade de recursos que requeiram um prazo relativamente longo para sua obtenção, sendo necessário haver uma conexão entre os planos de longo prazo e as atividades de curto prazo.

Tubino (2009) define que o planejamento mestre da produção (PMP) é o conector das atividades de longo prazo com as de curto prazo e Moreira (2008) 
complementa que o PMP é apropriado para avaliar as necessidades imediatas de capacidade produtiva, além disso, servirá para definir compras eventualmente necessárias e estabelecer prioridades entre os produtos da programação.

No que tange ao curto prazo, Tubino (2009) afirma a programação da produção é responsável por sequenciar as ordens emitidas no sentido de minimizar os lead times e estoques do sistema. Para programar a produção é necessário definir o tipo de sequenciamento que pode ser utilizado.

As regras de sequenciamento mais aplicadas estão expostas no Quadro 1.

Quadro 1- Sequenciamento de Programação da Produção

\begin{tabular}{|c|c|l|}
\hline Sigla & Especificação & \multicolumn{1}{c|}{ Definição } \\
\hline PEPS ou FIFO & $\begin{array}{c}\text { Primeira que entra Primeira } \\
\text { que sai (First in First out) }\end{array}$ & $\begin{array}{l}\text { Os lotes são processados de acordo com sua } \\
\text { chegada ao recurso }\end{array}$ \\
\hline UEPS ou LIFO & $\begin{array}{l}\text { Último que entra Primeiro } \\
\text { que Sai (Last in First Out) }\end{array}$ & $\begin{array}{l}\text { Os últimos lotes que chegaram ao recurso são } \\
\text { processados primeiro. }\end{array}$ \\
\hline MTP & $\begin{array}{l}\text { Menor tempo de } \\
\text { Processamento }\end{array}$ & $\begin{array}{l}\text { Os lotes são processados de acordo com as } \\
\text { menores datas de entrega. }\end{array}$ \\
\hline MDE & Menor data de entrega & $\begin{array}{l}\text { Os lotes são processados de acordo com as } \\
\text { menores datas de entrega, ou seja, é sequenciado } \\
\text { de acordo com a data prometida de entrega. }\end{array}$ \\
\hline IPI & Índice de Prioridade & $\begin{array}{l}\text { Os lotes são processados de acordo com o valor da } \\
\text { prioridade atribuída ao cliente ou produto, } \\
\text { independente da ordem de chegada do consumidor } \\
\text { ou do item. }\end{array}$ \\
\hline
\end{tabular}

Fonte: Adaptado de Slack et al. (2009) e Tubino (2009)

A discussão sobre o sequenciamento de programação da produção colabora para o entendimento do funcionamento do PPCP, na busca da diferenciação quanto ao preço, qualidade e prazo de entrega.

O mercado quer baixo custo, produtos de alta qualidade e que estejam disponíveis dentro de um curto prazo de entrega, enquanto as empresas desejam ter alta produtividade, lead times curtos e estoques mínimos. Com esses objetivos, o PPCP está sendo convidado a responder as mudanças internas e externas, pois se gerenciado de forma correta, promove um melhor controle de recursos e aumento da produtividade (BONNEY, 2000).

Por conseguinte, o processo de gestão deve ser aliado ao PPCP, a gestão de custos e a gestão da capacidade. Desta forma, auxilia o controle de recursos, podendo ser estimado o quanto será produzido, fato que afetará os custos unitários 
de cada produto fabricado, sendo necessário, portanto, discutir sobre a gestão de custos.

\subsection{Gestão de Custos}

Para Kunh et al. (2011) a gestão de custos objetiva auxiliar o planejamento e a mensuração do desempenho da empresa através do conhecimento do custo unitário dos produtos, sendo o custo unitário obtido através da contabilidade de custos.

A contabilidade de custos se destina a produzir informações para os diversos níveis gerenciais, para auxiliar as funções de desempenho, planejamento e controle das operações e das tomadas de decisões, sendo necessário, um sistema de custo que produza tais informações de acordo com as necessidades da empresa (LEONE, 2000).

Os sistemas de custos devem ser elaborados considerando as diferentes necessidades dos usuários, pois é necessário definir as características da entidade, seu ramo de atividade e elementos como: tamanho, natureza, estrutura organizacional, localização etc. Os principais métodos de custeio são: Custo Padrão, Centro de Custos, Baseado em Atividades e Unidade Esforço de Produção. São comentados acerca dos principais métodos de custeio Quadro 2. 
Quadro 2- Principais métodos de Custeio

\begin{tabular}{|c|c|}
\hline $\begin{array}{l}\text { Custo } \\
\text { Padrão }\end{array}$ & $\begin{array}{l}\text { Operacionaliza o custo a partir da soma dos custos de matéria prima e mão de obra } \\
\text { direta. O método não apura os custos indiretos de fabricação, necessita de outro } \\
\text { método associado, também não serve para gerenciar os custos, já que não oferece o } \\
\text { custo total por produto. }\end{array}$ \\
\hline $\begin{array}{l}\text { Centro de } \\
\text { Custos }\end{array}$ & $\begin{array}{l}\text { Operacionaliza o custo a partir da soma dos custos de matéria prima e mão de obra } \\
\text { direta, horas máquina e custos indiretos de fabricação (CIFs). É mais complexo que o } \\
\text { Custo Padrão, porém mais preciso na apuração e serve para gerenciar, pois informa a } \\
\text { totalização dos custos por processo e por produto. É um método tradicional, o que } \\
\text { significa que a apuração dos CIFs é baseado em direcionadores menos precisos, } \\
\text { porém é mais fácil de implantar e operacionalizar. Indicado para processos produtivos } \\
\text { pouco complexos e com pouca variedade. }\end{array}$ \\
\hline $\begin{array}{l}\text { Baseado } \\
\text { em } \\
\text { Atividades }\end{array}$ & $\begin{array}{l}\text { Busca identificar as atividades relevantes que geram os custos necessários para a } \\
\text { fabricação dos produtos. Operacionaliza o custo a partir do mapeamento de atividades } \\
\text { e recursos, é um método sistêmico, dado que considera que o custo não está } \\
\text { localizado em centros, mas sim em atividades. É considerado mais completo e mais } \\
\text { complexo que os métodos tradicionais, porém de mais difícil implantação e } \\
\text { operacionalização. Indicado para processos produtivos muito complexos, com alta } \\
\text { variedade e com mão de obra especializada.. }\end{array}$ \\
\hline $\begin{array}{l}\text { Unidade de } \\
\text { Esforço de } \\
\text { Produção }\end{array}$ & $\begin{array}{l}\text { Operacionaliza o custo a partir do esforço de produção que é gerado para elaborar os } \\
\text { produtos. Para implementá-lo divide-se a empresa em Postos Operativos. O custo de } \\
\text { matéria prima é calculado separadamente, podendo ser usado com associação ao } \\
\text { custo padrão. Indicado para empresa intensiva em máquinas e com alta variedade de } \\
\text { produtos. }\end{array}$ \\
\hline
\end{tabular}

Fonte: Bornia (2009), Bruni e Famá (2008), Gantzel e Allora (1996), Martins (2008), Stieg et al. (2011).

Estes são os principais métodos para apurar e gerenciar os custos. Como a empresa em estudo possui baixa variedade de produtos e um sistema de produção relativamente simples, foi escolhido o Método centro de custos. Além disso, conforme advoga Reis (2008) o método centro de custos é a técnica de alocação de custos mais utilizada no Brasil e no mundo.

Bornia (2009) afirma que o método Centro de Custos tem como fundamento a divisão da empresa em centros que consomem os custos e as despesas. De acordo com o autor, as etapas do método são: 1)Separação dos custos em itens; 2) Divisão da empresa em centros de custos; 3)Identificação dos custos com os centros (distribuição primária); 4) Distribuição dos custos dos centros indiretos até os diretos (distribuição secundária); 5) Distribuição dos custos dos centros diretos aos produtos (distribuição final). Tais etapas foram seguidas na elaboração deste artigo e os custos unitários de fabricação variam de acordo com a capacidade utilizada, sendo necessário discutir a gestão de capacidade. 


\subsection{Gestão da Capacidade}

De acordo com Jack e Powers (2009), um dos desafios mais significativos que enfrentam os gerentes é a necessidade de adequar a procura com a capacidade de produção em um ambiente industrial. Para Hynes (2009), é necessário que haja um conhecimento sobre gestão da capacidade, para que o trabalho seja concluído no prazo e em determinadas especificações. Para Pacheco et al. (2012), a habilidade de medir, compreender e gerenciar a capacidade torna-se crítica, para uma administração eficaz da produção. Corrêa e Corrêa (2007) afirmam que capacidade é o volume máximo de atividade de agregação de valor que pode ser atingido por uma unidade produtiva em condições normais de operação. Além do conceito de capacidade, é necessário conhecer os tipos de capacidade encontrados na literatura.

A capacidade de projeto (capacidade instalada ou ainda, capacidade teórica) é dificilmente atingida na prática, definindo-se como a produção máxima que pode ser atingida em um determinado período de tempo. A capacidade prática (efetiva) é a produção obtida em condições reais de funcionamento, considerando o tempo para preparar e ajustar as máquinas, além de outros fatores como dias de descanso, tempo de inatividade, e assim por diante. Além de considerar a tais definições, existe ainda uma capacidade real esperada que representa o nível médio anual de operação necessário para satisfazer a demanda em um período de tempo (MONTAÑES, GARCIA, 2011; SNEAD, STOTT, GARCIA; 2010). As definições supracitadas podem ser visualizadas na Figura 1.

Figura 1- Capacidade Projeto (Instalada), Efetiva (Prática) e Real Esperada (Atual)

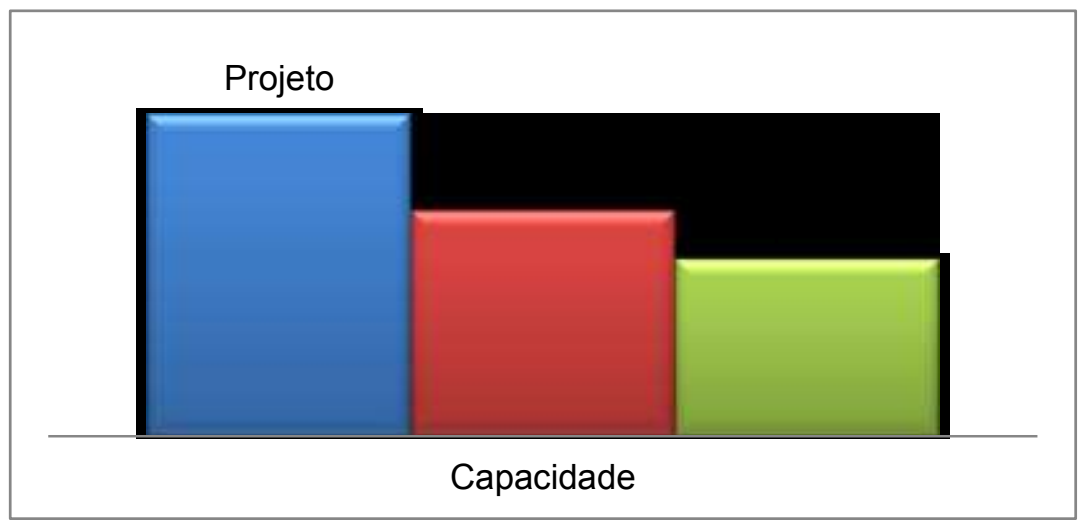

Fonte: Adaptado de Montañes e Gracia (2011, p. 102) 
Considerando as capacidades que foram expostas na Figura 1, estabelece a importância de um planejamento para que a capacidade real convirja para a capacidade efetiva, ou até mesmo a de projeto.

Soares (2007) afirma que equilíbrio adequado entre capacidade e demanda, pode gerar altos lucros e clientes satisfeitos, enquanto o equilíbrio "errado" pode ser potencialmente desastroso. Seguindo a mesma linha de raciocínio o autor afirma que as decisões acerca de capacidade têm impacto sobre toda empresa, sendo sua essência conciliar a capacidade com o nível de demanda que deve ser satisfeita.

A capacidade da fábrica indica a disponibilidade dos recursos produtivos, o que influencia diretamente os custos unitários. Desta forma, os passos seguidos para determinação do custo unitário e a relação com a capacidade é descrito na sequência.

\section{PROCEDIMENTOS METODOLÓGICOS}

A presente pesquisa pode ser classificada como aplicada e descritiva, visto que, os resultados gerados podem ser aplicados na solução de problemas, descrevendo fatos que foram analisados, não objetivando a modificação destes. O método aplicado foi o estudo de caso, sendo este um dos métodos mais comuns aplicados na engenharia de produção, conforme Miguel (2007).

O método estudo de caso permite aos pesquisadores manter a holística e as características significativas do evento, como ciclos de vida, comportamento de um pequeno grupo, processos administrativos e organizacionais (Yin, 2009). Além disto, o método é uma análise aprofundada de um ou mais objetos, com o uso de múltiplos instrumentos de coleta de dados e interação entre o pesquisador e o objeto de pesquisa (Nakano, 2010), sendo um dos métodos de pesquisas mais poderosos na gestão de operações, especialmente no desenvolvimento de novas teorias (Voss; Tsikriktsis; Frohlich, 2002).

Entretanto, deve-se tomar alguns cuidados para que a pesquisa torne-se confiável e representativa. Visando melhorar os efeitos da representatividade, Miguel (2007) aponta alguns elementos para a condução da pesquisa, a saber: 1) Definir uma estrutura conceitual teórico, com o objetivo de delimitar as fronteiras e grau de 
evolução; 2) Planejar os casos, devendo ser selecionado as unidades de análise e escolher meios para coletar e analisar os dados; 3) Conduzir o teste piloto, para testar procedimentos de aplicação, verificar a qualidade dos dados e fazer os ajustes necessários; 4) Coletar os dados; 5) Analisar os dados, produzindo uma narrativa e identificar causalidade; e por fim, 6) Gerar relatórios, onde deve desenhar as implicações teóricas e prover estrutura para replicação. Tais etapas são mostradas na Figura 2.

Figura 2 - Condução do Estudo de Caso

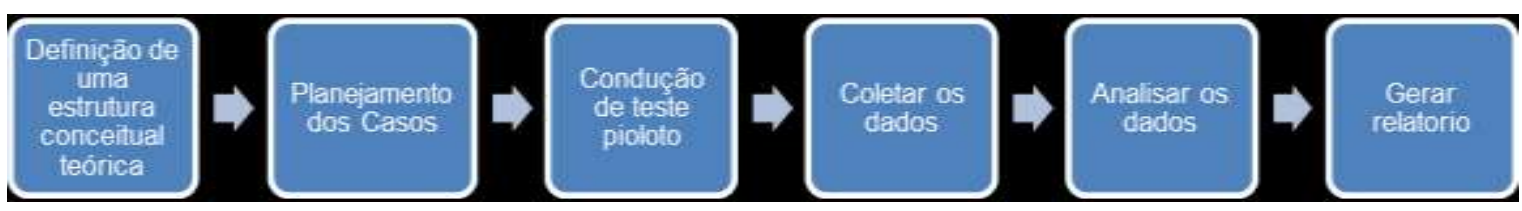

Fonte: Miguel (2007)

Para definição de uma estrutura conceitual teórica foi realizado um mapeamento da literatura acerca dos temas: PPCP, Gestão de Custos e Gestão da capacidade, explicitando a ligação entre os temas. Para o planejamento dos casos foi selecionada a empresa a ser estudada, bem como foi definida a equipe envolvida para a execução do trabalho, a saber: Diretores, Gerente de PPCP, Gerente de Vendas, Responsável financeiro, Contador e líderes dos centros de produção. Para a condução do teste piloto, foram elaborados roteiros de entrevistas semiestruturadas, bem como os ajustes necessários para a condução da pesquisa.

$\mathrm{Na}$ etapa de coleta de dados, foram aplicados os questionários, entrevistando a equipe envolvida no processo e solicitado os dados para a aplicação do método. Para a análise dos dados e elaboração do relatório, foram utilizadas planilhas no Microsoft Excel.

As etapas e passos seguidos são elencados a seguir. 


\subsection{Conhecimento e Análise do Processo Produtivo}

A partir de observações, entrevistas ao responsável do PPCP, responsável por vendas e perguntas aos funcionários, foi possível ter conhecimento de informações sobre o processo produtivo. Os passos foram:

a) Conhecer a história da empresa e o contexto o qual ela está inserida;

b) Entrevistas com o responsável de PPCP, responsável por vendas e discussões com os líderes de turma para detalhar o processo;

c) Conhecimento do PPCP.

\subsection{Coleta de Dados}

Com o intuito de coletar os dados para essa pesquisa, foram seguidos os seguintes passos:

a) Entrevistas com o responsável do setor financeiro, contador da empresa e diretores para identificar os itens de custos;

b) Solicitação dos dados ao setor financeiro, compras realizadas pelo almoxarifado e relatório contábil ao contador da empresa.

\subsection{Aplicação do método do Centro de Custos}

Nesta etapa, foram seguidos os passos descritos na sequência.

a) Levantamento dos itens de custos;

b) Divisão da empresa em centros;

c) Distribuição Primária: Identificação dos itens de custos (realizado em 'a') com os centros (realizado em 'b');

d) Distribuição Secundária: Alocar os centros indiretos aos diretos de acordo com os critérios escolhidos;

e) Distribuição Final: Alocar os custos dos centros diretos aos produtos. 


\subsection{Relação entre a Gestão da Capacidade e Gestão de Custos}

Esta etapa consiste em relacionar a capacidade efetiva e a capacidade real com os custos. Para isto, foram seguidos tais passos:

a) Verificação da capacidade média utilizada no período da pesquisa;

b) Comparação da capacidade utilizada com a efetiva;

c) Comparação do lucro com a capacidade utilizada e capacidade efetiva.

\section{ANÁLISE DA INFLUÊNCIA DA CAPACIDADE NA GESTÃO DOS CUSTOS UNITÁRIOS DE FABRICAÇÃO}

Foram levantadas características do PPCP, posteriormente a aplicação do método centro de custos, evidenciando a influência da capacidade na determinação do custo unitário.

\subsection{Caracterização do PPCP}

Através de entrevistas, foi percebido que não há uma previsão de demanda, nem anual nem semestral, interferindo assim no planejamento mestre da produção (PMP). De acordo com observações feitas e reuniões que foram presenciadas podese afirmar que existe um plano mestre de produção "imaturo".

O plano mestre de produção consiste em avaliar quais são os pedidos firmes em carteira versus capacidade da fábrica. Com isto, o diretor avalia possíveis mercados, negocia preços e tenta conquistar novos clientes.

Sobre a programação, o cliente é o responsável pelo início do processo. Se for um novo pedido, o cliente deverá aguardar a aprovação pelo responsável do PPCP juntamente com o diretor da empresa. Essa aprovação analisa a viabilidade financeira e técnica do pedido, levando em consideração as especificações exigidas. Consolidando a aprovação do pedido, o mesmo se destina ao PPCP que programa as ordens para cada centro produtivo deste pedido.

Quanto às funções do PPCP, iniciando pela gestão de estoques, pode-se dizer que há um abastecimento correto de matéria prima (MP). Quando chega uma 
ordem de produção (OP) para a extrusão, o líder da turma se encaminha ao almoxarifado, solicitando a MP para iniciar a produção.

Depois de concluída a ordem de fabricação no centro produtivo, o líder encaminha essa ordem ao setor de PPCP para o mesmo fazer o apontamento das vias. Todavia, não é possível saber quantas ordens de cada centro foi emitida por mês, visto que o apontamento nem sempre é feito, prejudicando assim o acompanhamento da produção.

A empresa possui um PPCP de fila, ou seja, cada pedido que chega segue o sequenciamento PEPS, exceto para aqueles pedidos "fora de hora" em que o cliente solicita urgência no atendimento, para assim viabilizar a compra.

Após discutir o os aspectos relacionados ao PPCP, faz-se necessário debater sobre o objetivo principal deste trabalho, a aplicação do método do centro de custos.

\subsection{Aplicação do método de centros de custos (RKW)}

Deste ponto em diante, é aplicado o método do centro de custos, que foi dividido em cinco etapas: identificação dos itens de custo, divisão da empresa em centros de custo, identificação dos custos com os centros, alocação dos custos dos centros indiretos aos diretos e distribuição dos custos aos produtos.

\subsubsection{Levantamento dos Itens de Custo}

Os itens de custos foram extraídos de uma classificação usada pela contabilidade e estão expostos no Quadro 3. 
Quadro 3 - Descrição dos Itens de Custo Identificados

\begin{tabular}{|c|c|}
\hline Item de Custo & Base de Alocação e Justificativa \\
\hline Clicheria & $\begin{array}{l}\text { Direto. Item alocado no Centro de Impressão, visto que é um custo de } \\
\text { fabricação deste Centro }\end{array}$ \\
\hline Comunicações & Direto. Item consumido pelo Centro Indireto Administração \\
\hline $\begin{array}{l}\text { Serviço Terceirizado de } \\
\text { Contabilidade }\end{array}$ & Direto. Item consumido pelo Centro Indireto Administração \\
\hline Energia Elétrica Tarifa Normal & $\begin{array}{l}\text { Potência Elétrica. Foi obtido multiplicando-se: o consumo em KWh do centro } \\
\text { x quantidade de horas utilizadas no horário de tarifa normal x tarifa horário } \\
\text { normal }\end{array}$ \\
\hline $\begin{array}{l}\text { Energia Elétrica Tarifa Horário de } \\
\text { Ponta }\end{array}$ & $\begin{array}{l}\text { Potência Elétrica. Foi obtido multiplicando-se: o consumo em KWh do centro } \\
\text { x quantidade de horas utilizadas no horário de tarifa de ponta } x \text { tarifa horário } \\
\text { de ponta }\end{array}$ \\
\hline Energia Elétrica Tarifa Gerador & $\begin{array}{l}\text { Potência Elétrica. Foi obtido multiplicando-se: o consumo em KWh do centro } \\
\text { que utiliza este recurso x quantidade de horas utilizadas no gerador } x \text { tarifa } \\
\text { gerador }\end{array}$ \\
\hline Água & $\begin{array}{l}\text { Direto. Optou-se por alocar no centro de Administração, já que não há } \\
\text { consumo de água nos outros centros }\end{array}$ \\
\hline Fardamento e EPI & $\begin{array}{l}\text { Direto. Item será alocado de acordo com o número de funcionários de cada } \\
\text { centro }\end{array}$ \\
\hline Vale Transporte & $\begin{array}{l}\text { Direto. Item será alocado de acordo com o número de funcionários de cada } \\
\text { centro }\end{array}$ \\
\hline Frete & $\begin{array}{l}\text { Direto. Item alocado no Centro de Administração, visto que este engloba o } \\
\text { departamento de Expedição. }\end{array}$ \\
\hline IPTU/TCR & Direto. Item alocado no igualmente para os centros diretos. \\
\hline $\begin{array}{l}\text { Manutenção e Conservação de } \\
\text { Bens e Veículos }\end{array}$ & Direto. Item alocado no Centro Indireto Administração \\
\hline Combustíveis & $\begin{array}{l}\text { Direto. Item alocado no Centro Administração, visto que este item é } \\
\text { destinado aos funcionários apenas deste Centro }\end{array}$ \\
\hline Material de Expediente & Direto. Item alocado no Centro Administração \\
\hline Microsiga & $\begin{array}{l}\text { Número de Computadores. Item alocado de acordo com o número de } \\
\text { computadores de cada Centro }\end{array}$ \\
\hline Salário Diretoria & Direto. Item alocado no Centro Administração \\
\hline Salário Almoxarifado & Direto. Item alocado no Centro Administração \\
\hline Salário Corte/Solda & Direto. Item alocado no Centro Corte/Solda \\
\hline Salário Expedição & Direto. Item alocado no Centro Administração \\
\hline Salário Extrusão & Direto. Item alocado no Centro Corte/Solda \\
\hline Salário Fábrica & $\begin{array}{l}\text { Direto. Item alocado no Centro Administração, visto que este item engloba } \\
\text { os salários do responsável de RH e financeiro }\end{array}$ \\
\hline Salário Vendas & Direto. Item alocado no Centro Administração \\
\hline Salário Gerência de Produção & $\begin{array}{l}\text { Direto. Item alocado no Centro de PPCP, visto que este centro é o que mais } \\
\text { se identifica com tal item de custo. }\end{array}$ \\
\hline Salário Impressão & Direto. Item alocado no Centro Impressão \\
\hline Salário Manutenção & $\begin{array}{l}\text { Direto. Item alocado no Centro de PPCP, visto que este centro é o que mais } \\
\text { se identifica com tal item de custo. }\end{array}$ \\
\hline Salário PPCP & Direto. Item alocado no Centro de PPCP \\
\hline Salário Qualidade & Direto. Item alocado no Centro de Qualidade \\
\hline Salário Recuperação & Direto. Item alocado no Centro de Recuperação \\
\hline Salário Refile & Direto. Item Alocado no Centro de Refile \\
\hline Salário Serviços Gerais & Direto. Item alocado no Centro de Administração \\
\hline Remuneração dos Estagiários & Direto. Item alocado no Centro de Administração \\
\hline Depreciação & $\begin{array}{l}\text { Direto. Item alocado no centro de Extrusão, visto que a única máquina que } \\
\text { foi considerada a depreciação corresponde a este centro }\end{array}$ \\
\hline Taxas Financeiras & $\begin{array}{l}\text { Direto. Item alocado no Centro de Administração, visto que este gasto } \\
\text { corresponde as atividades financeiras da empresa }\end{array}$ \\
\hline
\end{tabular}

Fonte: Elaboração dos Autores

Revista Produção Online, Florianópolis, SC, v.13, n. 3, p. 915-944, jul./set. 2013. 
Os gastos foram obtidos por uma média de quatro meses do ano, através dos relatórios contábeis e do sistema Microsiga. Após o levantamento dos itens de custos, a segunda etapa do método é dividir a empresa em centros diretos e indiretos.

\subsubsection{Divisão da empresa em Centros Diretos e Indiretos}

Para esta segunda etapa a empresa em estudo foi separada em oito centros: extrusão, impressão, refile, corte/solda, recuperação, administração, PPCP e qualidade, onde os cinco primeiros centros são diretos e os demais são indiretos. $O$ centro administração corresponde às funções de almoxarifado, expedição, serviços

gerais e fábrica. O centro de PPCP corresponde a funções relacionadas com o planejamento da produção, onde incluirá os responsáveis pela manutenção, já o centro de Qualidade concerne a parte da empresa responsável pelo controle de qualidade.

Os centros diretos são bem definidos, sendo cada um deles possuindo funcionários que trabalham apenas naquele setor. Os centros são compostos pelas máquinas já identificadas anteriormente e seu consumo em kWh foi obtido através de medições realizadas pelo setor de manutenção, feitas em todas as máquinas. No centro refile e corte/solda os equipamentos possuem a mesma referência e assim, o mesmo consumo. Todas essas informações estão presentes na Tabela 1. 
Tabela 1- Consumo de cada máquina em kWh e seu funcionamento

\begin{tabular}{|c|c|c|c|c|c|}
\hline Centro & Máquina & $\begin{array}{l}\text { Consumo } \\
\text { em kWh }\end{array}$ & $\begin{array}{c}\text { Horas } \\
\text { Funcionamento } \\
\text { no Horário } \\
\text { Normal por } \\
\text { mês }\end{array}$ & $\begin{array}{c}\text { Horas } \\
\text { Funcionamento } \\
\text { no Horário de } \\
\text { Ponta por mês }\end{array}$ & $\begin{array}{c}\text { Horas } \\
\text { Funcionamento } \\
\text { no Gerador por } \\
\text { mês }\end{array}$ \\
\hline \multirow{5}{*}{ Extrusão } & CHD-50 & 21 & 654 & & 66 \\
\hline & CHD-60 & 32,4 & 654 & & 66 \\
\hline & CHD-70 & 46,2 & 654 & & 66 \\
\hline & E 50 & 13,2 & 654 & 66 & \\
\hline & HGR-65 & 36 & 654 & 66 & \\
\hline \multirow{3}{*}{ Impressão } & Flexo & 7,8 & 502 & 44 & \\
\hline & Feva & 18 & 502 & 44 & \\
\hline & Thunder & 38,4 & 502 & & 44 \\
\hline \multirow[t]{2}{*}{ Refile } & Refile & $5(\mathrm{kWh}) \times 3$ & & & \\
\hline & & $\begin{array}{c}\text { máquinas }= \\
15\end{array}$ & 502 & & 44 \\
\hline \multirow[t]{3}{*}{ Corte Solda } & Corte/Solda & $3(\mathrm{kWh}) \times 9$ & & & \\
\hline & & (máquinas) & 502 & & 44 \\
\hline & & $=27$ & & & \\
\hline \multirow{2}{*}{ Recuperação } & Aglutinador & 36 & 570 & & \\
\hline & Recuperadora & 31,2 & 570 & & \\
\hline
\end{tabular}

Fonte: Departamento de Manutenção da Empresa em Estudo

É importante frisar que para indústria, existem duas tarifas de energia elétrica (EE): em horário de ponta e tarifa normal. Não obstante, a fábrica possui um gerador próprio para ser utilizada nos horários em que a EE se torna mais onerosa, porém, o gerador é utilizado em apenas algumas máquinas. O horário de ponta acontece segunda a sexta das 17:30 às 20:30 horas.

Ainda sobre o consumo de EE, existem sete aparelhos de ar condicionados, sendo seis de modelo tipo janela (abaixo de 9.000 BTU) e um tipo Split. Os aparelhos ficam ligados cerca de 8 horas por dia, em horário comercial (segunda a sexta, 8:00 às 12:00 e 14:00 às 18:00), implicado que os aparelhos funcionarão 30 minutos em horário de ponta e nas demais antes em horário normal. O consumo de cada aparelho está colocado na Tabela 2. 
Tabela 2- Consumo dos Aparelhos Eletrônicos

\begin{tabular}{ccc}
\hline Quantidade & Aparelho & Consumo kWh \\
\hline 1 & Ar condicionado Split 30.000 BTU'S & 3,17 \\
7 & Ar Condicionado Tipo Janela Menor ou Igual a 9.000 BTU'S & $0,5366^{\star} 7=3,7562$
\end{tabular}

Fonte: Adaptado de Eletrobrás (2011)

O ar condicionado tipo Split fica na parte do departamento financeiro, já os tipo janela fica um em cada sala: Vendas, Qualidade, PPCP, almoxarifado, Expedição, Diretoria 1 e Diretoria 2.

\subsubsection{Identificação dos custos com os centros}

Esta etapa pode ser chamada também de distribuição primária, que consistem em alocar os itens de custos (Quadro 3), identificados na etapa anterior, nos respectivos centros.

É importante frisar que as duas tarifas de energia elétrica estão presentes na própria fatura de energia elétrica, já a tarifa do gerador foi fornecida pelo setor de manutenção para este trabalho, a Tabela 3 mostra as tarifas usadas neste trabalho.

Tabela 3- Tarifas de EE em $\mathrm{R} \$ / \mathrm{kWh}$

\begin{tabular}{cc}
\hline Descrição & Valor (R\$/kWh) \\
\hline Tarifa Horário de Ponta & 2,25405 \\
Tarifa Fora do Horário de Ponta & 0,21571 \\
Tarifa Gerador & 0,51 \\
\hline
\end{tabular}

Fonte: Fatura de Energia Elétrica e Departamento de Manutenção

O custo de energia elétrica pode ser obtido multiplicando o valor da tarifa (Tabela 3) pelo número de horas que o equipamento utiliza da tarifa e a potência do equipamento em kWh (Tabela $1 \mathrm{e} \quad$ Tabela 2). O custo obtido na distribuição primária de cada centro encontra-se na Tabela 4. 
Tabela 4- Custo dos Centros Diretos e Indiretos

\begin{tabular}{ccc}
\hline & Centro & Custo Centro (R\$) \\
\hline \multirow{2}{*}{ Indireto } & Administração & $80.042,58$ \\
& PPCP & $14.017,17$ \\
& Qualidade & $4.388,12$ \\
& Extrusão & $53.221,09$ \\
& Impressão & $37.837,57$ \\
Direto & Refile & $10.652,33$ \\
& Corte/Solda & $30.872,85$ \\
& Recuperação & $14.464,90$
\end{tabular}

Fonte: Elaboração dos Autores

4.2.4 Alocação dos Custos dos Centros Indiretos aos Diretos

Nesta etapa os centros indiretos são alocados aos centros diretos, de acordo com o critério escolhido. Para o centro de Administração foi escolhido o tempo de produção disponível de cada centro direto.

O setor de PPCP não dispõe da quantidade de ordens emitidas para cada centro. Assim, o critério estabelecido para a distribuição do PPCP aos demais centros diretos, foi a média de quatro meses de quilos produzidos nos centros.

A distribuição do centro de qualidade aos demais centros diretos, foi feito em termos de porcentagem, sendo dedicados $50 \%$ a extrusão, $30 \%$ para impressão, $5 \%$ para o refile e $15 \%$ para o corte/solda. O centro de recuperação não interage com o de qualidade. Por fim, a distribuição secundária é apresentada na Tabela 5.

Tabela 5- Distribuição Secundária

\begin{tabular}{cccccc}
\hline Centro & Extrusão & Impressão & Refile & Corte/solda & Recuperação \\
\hline Custo do Centro $(\mathrm{R} \$)$ & $53.221,09$ & $37.837,57$ & $10.652,33$ & $30.872,85$ & $14.464,90$ \\
Administração $(\mathrm{R} \$)$ & $19.682,60$ & $14.925,97$ & $14.925,97$ & $14.925,97$ & $15.582,06$ \\
PPCP $(\mathrm{R} \$)$ & $5.135,82$ & $3.043,72$ & $2.895,85$ & $2.256,46$ & 685,32 \\
Qualidade $(\mathrm{R} \$)$ & $2.194,06$ & $1.316,44$ & 219,41 & 658,22 & 0,00 \\
Total $(\mathrm{R} \$)$ & $80.233,58$ & $57.123,70$ & $28.693,55$ & $48.713,50$ & $30.732,28$
\end{tabular}

Fonte: Elaboração dos Autores 


\subsubsection{Distribuição Final}

Para distribuição final, são consideradas as capacidades nominais dos centros e as horas disponíveis mês. Para melhor visualização da capacidade nominal foi elaborada a Tabela 6.

Tabela 6- Capacidade Nominal da Fábrica

\begin{tabular}{cccc}
\hline Centro & $\begin{array}{c}\text { Capacidade em } \\
\text { Kg/Hora }\end{array}$ & $\begin{array}{c}\text { Horas Totais } \\
\text { Disponíveis por mês }\end{array}$ & $\begin{array}{c}\text { Capacidade de Projeto } \\
\text { Kg/mês }\end{array}$ \\
\hline Extrusão & 590 & 720 & 424.800 \\
Impressão & 750 & 546 & 409.500 \\
Refile & 600 & 546 & 327.600 \\
Corte/Solda & 425 & 546 & 232.050 \\
Recuperação & 126 & 570 & 71.820 \\
\hline
\end{tabular}

Fonte: Elaboração dos Autores

Entretanto, a capacidade de projeto da fábrica não considera paradas para manutenção, set up para troca de pedido, troca de turno, etc. Não há um acompanhamento efetivo da produção, para mensurar quanto tempo as máquinas ficam paradas e os motivos. Assim, esses valores foram estimados de acordo com observações e entrevistas informais.

Para extrusão, as paradas por troca de pedido consomem em média 20 horas por mês, já as paradas para acerto do material (espessura, largura, etc) levam em torno de 14 horas por mês, sendo as paradas para acerto o momento em que se produz apara. Logo, a quantidade de horas paradas para acerto multiplicado pela capacidade em $\mathrm{Kg} / \mathrm{h}$ ora da máquina resulta no total de apara por mês, que é de $2,5 \%$ em relação as horas de funcionamento da máquina. A capacidade efetiva da extrusão foi obtida pela multiplicação da capacidade deste centro em $\mathrm{Kg} / \mathrm{hora}$ pelas horas disponíveis, neste caso 682,5 horas por mês (720 menos 20 menos $17,5=682,5)$. Todo este processo foi feito para os demais centros, exceto o centro de recuperação. 
Tabela 7- Capacidade Efetiva por mês de cada centro

\begin{tabular}{|c|c|c|c|c|c|c|c|}
\hline \multirow[b]{2}{*}{ Centro } & \multirow[b]{2}{*}{ 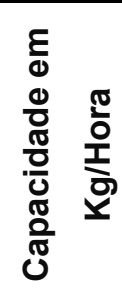 } & \multirow[b]{2}{*}{$\begin{array}{l}\frac{0}{\pi} \\
\frac{\pi}{0} \\
\frac{0}{0} \\
0 \\
\frac{0}{0} \\
\text { 우 }\end{array}$} & \multirow[b]{2}{*}{ 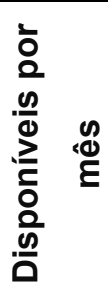 } & \multicolumn{2}{|c|}{ Set up } & \multirow[b]{2}{*}{$\begin{array}{l}\text { Total Apara } \\
\text { Kg por mês }\end{array}$} & \multirow[b]{2}{*}{ 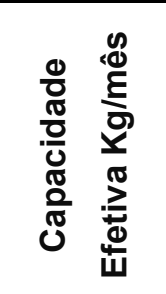 } \\
\hline & & & & $\begin{array}{c}\text { Parada para } \\
\text { Troca de } \\
\text { Pedido } \\
\text { (hora/mês) }\end{array}$ & $\begin{array}{c}\text { Paradas } \\
\text { para } \\
\text { Acerto } \\
\text { (hora/mês) }\end{array}$ & & \\
\hline Extrusão & 590 & & 720 & 20 & 17,5 & $\begin{array}{c}17,5 * 590= \\
10.325\end{array}$ & 402.675 \\
\hline Impressão & 750 & & 546 & 60 & 4,86 & $\begin{array}{c}4.86 * 750= \\
3.645\end{array}$ & 357.210 \\
\hline Refile & 600 & & 546 & 4 & 8,13 & $\begin{array}{c}8,13^{*} 600= \\
4.878\end{array}$ & 321.948 \\
\hline Corte Solda & 425 & & 546 & 4 & 5,42 & $\begin{array}{c}5,42 * 425= \\
2.303,5\end{array}$ & $228.046,5$ \\
\hline
\end{tabular}

Fonte: Elaboração do Autor

$\mathrm{Na}$ Tabela 7 pode-se observar a capacidade nominal de cada centro produtivo. A capacidade de projeto do centro de recuperação é de 71.820 quilos por mês, sendo objetivo deste recuperar a apara que foi gerada no processo. Porém, somando-se a apara gerada pelos centros (Tabela 7), chega a um valor de $21.151,5$ $\mathrm{Kg}$, sendo este usado para a capacidade efetiva do centro. Ao dividir o custo do centro pela capacidade efetiva de cada um deles, resulta no custo unitário por quilo.

Para comparar o custo unitário por quilo utilizando a capacidade efetiva e a capacidade que está sendo utilizada, foi elaborada a Tabela 8. Esta capacidade utilizada foi fornecida pelo departamento de PPCP.

Tabela 8- Comparativo entre o Custo Unitário com a Capacidade Efetiva versus Capacidade Utilizada

\begin{tabular}{c|c|c|c|c}
\hline Centro & $\begin{array}{c}\text { Capacidade } \\
\text { Efetiva (Kg) }\end{array}$ & $\begin{array}{c}\text { Custo Unitário por Quilo } \\
\text { utilizando Capacidade Efetiva } \\
\text { (R\$) }\end{array}$ & $\begin{array}{c}\text { Capacidade } \\
\text { Utilizada }\end{array}$ & $\begin{array}{c}\text { Custo Unitário } \\
\text { Atual por Quilo (R\$) }\end{array}$ \\
\hline Extrusão & 402.675 & 0,20 & $176.298,32$ & 0,46 \\
Impressão & 357.210 & 0,16 & $104.482,35$ & 0,55 \\
Refile & 321.948 & 0,09 & $99.406,24$ & 0,29 \\
Corte/Solda & $228.046,50$ & 0,21 & $74.509,63$ & 0,65 \\
Recuperação & $21.151,50$ & 1,45 & $17.666,67$ & 1,74 \\
\hline
\end{tabular}

Fonte: Elaboração do Autor 
Com o intuito de visualizar a forma de utilização da capacidade foi elaborado o Gráfico 1.

Gráfico 1- Comparação entre a Capacidade de Projeto, Efetiva e Real na Empresa em Estudo

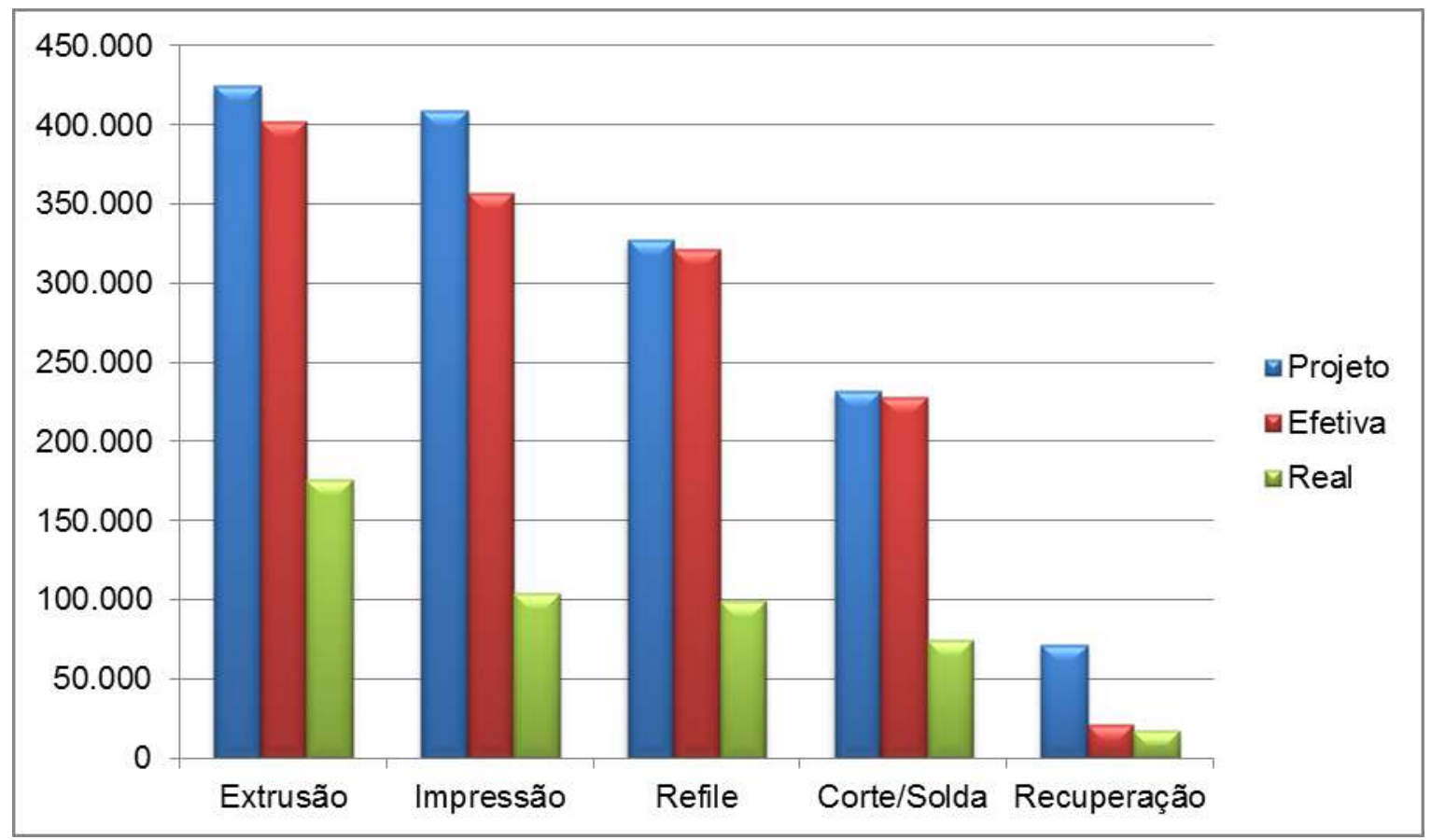

Fonte: Elaboração dos Autores

Para conhecer o custo unitário de cada produto, faz-se saber que a empresa possui um incentivo fiscal que possibilita a creditação de impostos, PIS e COFINS, sendo este crédito de 9,25\% sobre o valor da MP comprada.

Para a extrusão, o custo da MP para cada produto está na Tabela 9, além disto, todos os produtos usam MP Primária Extrusão, enquanto os filmes e sacarias usam, além da MP Primária, também as secundárias.

Tabela 9- Custo Matéria Prima para Extrusão

\begin{tabular}{c|c|c}
\hline Matéria Prima & Custo Médio (R\$) & $\begin{array}{c}\text { Custo com Creditação PIS/COFINS } \\
\text { (R\$) }\end{array}$ \\
\hline MP Primária Extrusão & 4,17 & 3,7843 \\
MP Secundária Extrusão & 0,33 & 0,2995 \\
Total & $\mathbf{4 , 5 0}$ & $\mathbf{4 , 0 8 3 8}$ \\
\hline
\end{tabular}

Fonte: Elaboração dos Autores

Revista Produção Online, Florianópolis, SC, v.13, n. 3, p. 915-944, jul./set. 2013. 
$\mathrm{Na}$ impressão, a MP foi classificada em duas categorias: a primária e a secundária. A primária corresponde as tintas e solventes consumidas no período e a secundária corresponde aos materiais aditivos, lâminas e fitas dupla face. O custo médio é disposto na Tabela 10, considerando que todos os produtos que passam pela impressão utilizam MP Primária e Secundária.

Tabela 10- Custo Matéria Prima para Impressão

\begin{tabular}{c|c|c}
\hline Matéria Prima & Custo Médio (R\$) & $\begin{array}{c}\text { Custo com Creditação PIS/COFINS } \\
\text { (R\$) }\end{array}$ \\
\hline MP Primária Impressão & 0,4403 & 0,3996 \\
MP Secundária Impressão & 0,0555 & 0,0507 \\
Total & $\mathbf{0 , 4 9 5 8}$ & $\mathbf{0 , 4 4 9 9}$ \\
\hline
\end{tabular}

Fonte: Elaboração dos Autores

Para a bobina lisa, os custos são colocados na Tabela 11, comparando-se utilizando a capacidade efetiva e a capacidade que está sendo utilizada. O custo sobre a apara foi calculado em porcentagem sobre o valor da MP, tanto no centro de extrusão, como no Refile.

Tabela 11- Custo da Bobina Lisa por Quilo

\begin{tabular}{l|c|c}
\hline \multicolumn{1}{c|}{ Bobina Lisa } & $\begin{array}{c}\text { Custo utilizando } \\
\text { Capacidade Efetiva (R\$) }\end{array}$ & $\begin{array}{c}\text { Custo utilizando } \\
\text { Capacidade Real (R\$) }\end{array}$ \\
\hline Extrusão & 0,20 & 0,46 \\
Refile & 0,09 & 0,29 \\
MP Primária Extrusão & 3,78 & 3,78 \\
Custo Apara sobre MP na Extrusão (2,5\%) & 0,09 & 0,09 \\
Custo Apara sobre MP no Refile (1,5\%) & 0,06 & 0,06 \\
Custo Total & $\mathbf{4 , 2 2}$ & $\mathbf{4 , 6 8}$ \\
\hline
\end{tabular}

Fonte: Elaboração dos Autores

Para a bobina impressa, o custo por quilo está na Tabela 12. O custo da apara sobre a extrusão foi calculado apenas sobre o valor da 'MP Primária Extrusão'. Já o custo da apara a impressão e no refile, foi calculado sobre o custo da ‘MP Primária Extrusão' e 'MP Impressão'. 
Tabela 12- Custo da Bobina Impressa por Quilo

\begin{tabular}{l|c|c}
\hline \multicolumn{1}{c|}{ Bobina Impressa } & $\begin{array}{c}\text { Custo utilizando } \\
\text { Capacidade Efetiva (R\$) }\end{array}$ & $\begin{array}{c}\text { Custo utilizando } \\
\text { Capacidade Real (R\$) }\end{array}$ \\
\hline Extrusão & 0,20 & 0,46 \\
Impressão & 0,16 & 0,55 \\
Refile & 0,09 & 0,29 \\
MP Primária Extrusão & 3,78 & 3,78 \\
MP Impressão & 0,45 & 0,45 \\
Custo Apara sobre MP na Extrusão (2,5\%) & 0,09 & 0,09 \\
Custo Apara sobre MP na Impressão (1\%) & 0,04 & 0,04 \\
Custo Apara sobre MP no Refile (1,5\%) & 0,06 & 0,06 \\
Custo Total & $\mathbf{4 , 8 2}$ & $\mathbf{5 , 6 6}$ \\
\hline
\end{tabular}

Fonte: Elaboração dos Autores

Para o filme técnico, o custo por quilo do produto, está destacado na Tabela 13 , sendo o custo da apara sobre MP na extrusão calculado de 2,5\% sobre o valor da MP Primária e Secundária na Extrusão. Já o custo da apara na impressão e no refile, foi calculado sobre toda a matéria prima envolvida no processo.

Tabela 13- Custo do Filme Técnico por Quilo

\begin{tabular}{l|c|c}
\hline \multicolumn{1}{c|}{ Filme Técnico } & $\begin{array}{c}\text { Custo utilizando } \\
\text { Capacidade Efetiva (R\$) }\end{array}$ & $\begin{array}{c}\text { Custo utilizando } \\
\text { Capacidade Real (R\$) }\end{array}$ \\
\hline Extrusão & 0,20 & 0,46 \\
Impressão & 0,16 & 0,55 \\
Refile & 0,09 & 0,29 \\
MP Primária Extrusão & 3,78 & 3,78 \\
MP Secundária Extrusão & 0,30 & 0,30 \\
MP Impressão & 0,45 & 0,45 \\
Custo Apara sobre MP na Extrusão (2,5\%) & 0,10 & 0,10 \\
Custo Apara sobre MP na Impressão (1\%) & 0,05 & 0,05 \\
Custo Apara sobre MP no Refile (1,5\%) & 0,05 & 0,05 \\
Custo Total & $\mathbf{5 , 1 3}$ & $\mathbf{5 , 9 7}$ \\
\hline
\end{tabular}

Fonte: Elaboração dos Autores

O custo por quilo da sacaria impressa frente, está na Tabela 14. 
Tabela 14- Custo da Sacaria Impressa Frente por Quilo

\begin{tabular}{l|c|c}
\hline \multicolumn{1}{c|}{ Sacaria Impressa Frente } & $\begin{array}{c}\text { Custo utilizando } \\
\text { Capacidade Efetiva (R\$) }\end{array}$ & $\begin{array}{c}\text { Custo utilizando } \\
\text { Capacidade Real (R\$) }\end{array}$ \\
\hline Extrusão & 0,20 & 0,46 \\
Impressão & 0,16 & 0,55 \\
Corte/Solda & 0,21 & 0,29 \\
MP Primária Extrusão & 3,78 & 3,78 \\
MP Secundária Extrusão & 0,30 & 0,30 \\
MP Impressão & 0,45 & 0,45 \\
Custo Apara sobre MP na Extrusão & 0,10 & 0,10 \\
Custo Apara sobre MP no Impressão & 0,05 & 0,05 \\
Custo Apara sobre MP no Corte/Solda & 0,05 & 0,05 \\
Custo Total R\$ & $\mathbf{5 , 2 5}$ & $\mathbf{5 , 9 7}$ \\
\hline
\end{tabular}

Fonte: Elaboração dos Autores

O custo por quilo da sacaria impressa frente e verso, e da sacaria lisa, estão colocados na Tabela 15 e Tabela 16, respectivamente.

Tabela 15- Custo da Sacaria Impressa Frente Verso por Quilo

\begin{tabular}{l|c|c}
\hline \multicolumn{1}{c|}{ Sacaria Impressa Frente Verso } & $\begin{array}{c}\text { Custo utilizando } \\
\text { Capacidade Efetiva (R\$) }\end{array}$ & $\begin{array}{c}\text { Custo utilizando } \\
\text { Capacidade Real (R\$) }\end{array}$ \\
\hline Extrusão & 0,20 & 0,46 \\
Impressão & 0,16 & 0,55 \\
Refile & 0,09 & 0,29 \\
Corte/Solda & 0,21 & 0,65 \\
MP Primária Extrusão & 3,78 & 3,78 \\
MP Secundária Extrusão & 0,30 & 0,30 \\
MP Impressão & 0,45 & 0,45 \\
Custo Apara sobre MP na Extrusão (2,5\%) & 0,10 & 0,10 \\
Custo Apara sobre MP na Impressão (1\%) & 0,05 & 0,05 \\
Custo Apara sobre MP no Refile (1,5\%) & 0,05 & 0,05 \\
Custo Apara sobre MP no Corte Solda (1\%) & 0,05 & 0,05 \\
Custo Total R\$ & $\mathbf{5 , 3 4}$ & $\mathbf{6 , 6 3}$ \\
\hline
\end{tabular}

Fonte: Elaboração dos Autores 
Tabela 16- Custo da Sacaria Lisa por Quilo

\begin{tabular}{l|c|c}
\hline \multicolumn{1}{c|}{ Sacaria Lisa } & $\begin{array}{c}\text { Custo utilizando } \\
\text { Capacidade Efetiva (R\$) }\end{array}$ & $\begin{array}{c}\text { Custo utilizando } \\
\text { Capacidade Real (R\$) }\end{array}$ \\
\hline Extrusão & 0,20 & 0,46 \\
Refile & 0,09 & 0,55 \\
Corte/Solda & 0,21 & 0,29 \\
MP Primária Extrusão & 3,78 & 3,78 \\
MP Secundária Extrusão & 0,30 & 0,30 \\
Custo Apara sobre MP na Extrusão (2,5\%) & 0,10 & 0,10 \\
Custo Apara sobre MP no Refile (1,5\%) & 0,06 & 0,06 \\
Custo Apara sobre MP no Corte/Solda (1\%) & 0,04 & 0,04 \\
Custo Total R\$ & $\mathbf{4 , 7 5}$ & $\mathbf{5 , 5 4}$ \\
\hline
\end{tabular}

Fonte: Elaboração dos Autores

Por fim, o custo da sacaria recuperada, foi colocado na Tabela 17.

Tabela 17- Custo da Sacaria Recuperada por Quilo

\begin{tabular}{l|c|c}
\hline Sacaria Recuperada & Custo com Capacidade Efetiva (R\$) & Custo com Capacidade Real (R\$) \\
\hline Extrusão & 0,20 & 0,46 \\
Corte/Solda & 0,21 & 0,65 \\
Recuperação & 1,45 & 1,74 \\
Custo Total R\$ & $\mathbf{1 , 8 7}$ & $\mathbf{2 , 8 5}$ \\
\hline
\end{tabular}

Fonte: Elaboração dos Autores

A Tabela 18 compara o custo dos produtos por quilo que pode ser obtido utilizando a capacidade efetiva e o custo real do período, com a capacidade atual utilizada.

Tabela 18- Comparação entre o Custo Utilizando a Capacidade Efetiva e Capacidade Utilizada

\begin{tabular}{lcc|c}
\hline \multicolumn{1}{c|}{ Produto } & $\begin{array}{c}\text { Custo utilizando } \\
\text { Capacidade Efetiva }\end{array}$ & $\begin{array}{c}\text { Custo utilizando } \\
\text { Capacidade Real }\end{array}$ & Diferença \\
\hline Bobina Lisa & 4,22 & 4,68 & $10,78 \%$ \\
Bobina Impressa & 4,82 & 5,66 & $17,47 \%$ \\
Filme Técnico & 5,13 & 5,97 & $16,42 \%$ \\
Sacaria Impressa Frente & 5,25 & 5,97 & $13,66 \%$ \\
Sacaria Impressa $\quad$ Frente & 5,34 & 6,63 & $24,00 \%$ \\
Verso & 4,75 & 5,54 & $16,60 \%$ \\
Sacaria Lisa & 1,87 & 2,85 & $52,66 \%$ \\
Sacola Recuperada & &
\end{tabular}

Fonte: Elaboração dos Autores

Revista Produção Online, Florianópolis, SC, v.13, n. 3, p. 915-944, jul./set. 2013. 
Entretanto, para obter o custo final por quilo de cada pedido, a empresa deve acrescer sobre o preço de venda: a comissão dos representantes (3\%), o custo financeiro do prazo de pagamento (2\%), e os impostos (1\% para ICMS e 9,25\% para PIS/COFINS). Os custos unitários atuais consideram a capacidade que está sendo utilizada atualmente e os encargos (impostos, comissões e financeiro) estão calculados sobre o atual preço de venda. Desta forma, essas informações estão organizadas na Tabela 19.

Tabela 19- Custo Final dos Produtos considerando a Capacidade Utilizada pela Empresa

\begin{tabular}{l|c|c|c|c}
\hline \multicolumn{1}{c|}{ Produto } & Custo Atual & $\begin{array}{c}\text { Encargos } \\
\text { Sobre Venda } \\
\text { Atual }\end{array}$ & $\begin{array}{c}\text { Preço de } \\
\text { Venda Médio } \\
\text { Atual }\end{array}$ & Margem Atual \\
\hline Bobina Lisa & 4,68 & 1,04 & 6,84 & 1,12 \\
Bobina Impressa & 5,66 & 1,11 & 7,30 & 0,53 \\
Filme Técnico & 5,97 & 1,11 & 7,25 & 0,17 \\
Sacaria Impressa Frente & 5,97 & 1,14 & 7,50 & 0,38 \\
Sacaria Impressa Frente Verso & 6,63 & 1,22 & 8,00 & 0,15 \\
Sacaria Lisa & 5,54 & 1,04 & 6,85 & 0,27 \\
Sacola Recuperada & 2,85 & 0,61 & 4,00 & 0,54 \\
\hline
\end{tabular}

Fonte: Elaboração dos Autores

A Tabela 20 mostra os custos obtidos através da aplicação do método Centro de Custos com a Capacidade Efetiva, considerando um preço de venda menor do que o praticado atualmente, o que tornaria a empresa mais competitiva. 
Tabela 20- Custo Final dos Produtos considerando a Capacidade Efetiva

\begin{tabular}{|c|c|c|c|c|}
\hline Produto & Custo Ideal & $\begin{array}{c}\text { Encargos } \\
\text { Sobre } \\
\text { Venda }\end{array}$ & $\begin{array}{c}\text { Preço de } \\
\text { Venda Médio } \\
\text { Proposto }\end{array}$ & Margem \\
\hline Bobina Lisa & 4,22 & 0,99 & 6,50 & 1,28 \\
\hline Bobina Impressa & 4,82 & 1,07 & 7,00 & 1,11 \\
\hline Filme Técnico & 5,13 & 1,04 & 6,80 & 0,63 \\
\hline Sacaria Impressa Frente & 5,25 & 1,07 & 7,00 & 0,68 \\
\hline Sacaria Impressa Frent & & & & \\
\hline Verso & 5,34 & 1,14 & 7,50 & 1,01 \\
\hline Sacaria Lisa & 4,75 & 0,99 & 6,50 & 0,76 \\
\hline Sacola Recuperada & 1,87 & 0,61 & 4,00 & 1,52 \\
\hline
\end{tabular}

Fonte: Elaboração dos Autores

Por fim, a Tabela 21 é um comparativo entre as Tabela 19 e Tabela 20, que demonstra o lucro (preço de venda menos custo) utilizando a capacidade atual versus capacidade efetiva.

Tabela 21- Comparação entre Lucro com o uso da Capacidade Utilizada e Capacidade Efetiva

\begin{tabular}{c|c|c}
\hline Produto & Margem Atual (R\$) & $\begin{array}{c}\text { Margem Utilizando } \\
\text { Capacidade Efetiva (R\$) }\end{array}$ \\
\hline Bobina Lisa & 1,12 & 1,28 \\
Bobina Impressa & 0,53 & 1,11 \\
Filme Técnico & 0,17 & 0,63 \\
Sacaria Impressa Frente & 0,38 & 0,68 \\
Sacaria Impressa Frente Verso & 0,15 & 1,01 \\
Sacaria Lisa & 0,27 & 0,76 \\
Sacola Recuperada & 0,54 & 1,52 \\
\hline
\end{tabular}

Fonte: Elaboração dos Autores

A Tabela 21 mostra que ao utilizar sua capacidade efetiva, diminuindo o preço de venda, para atrair novos clientes e pedidos, a margem aumenta, tornando-a assim mais atrativa para seus colaboradores e acionistas, formando um círculo virtuoso, conforme mostra a Figura 3. 
Figura 3- Círculo Virtuoso com a Gestão da Capacidade

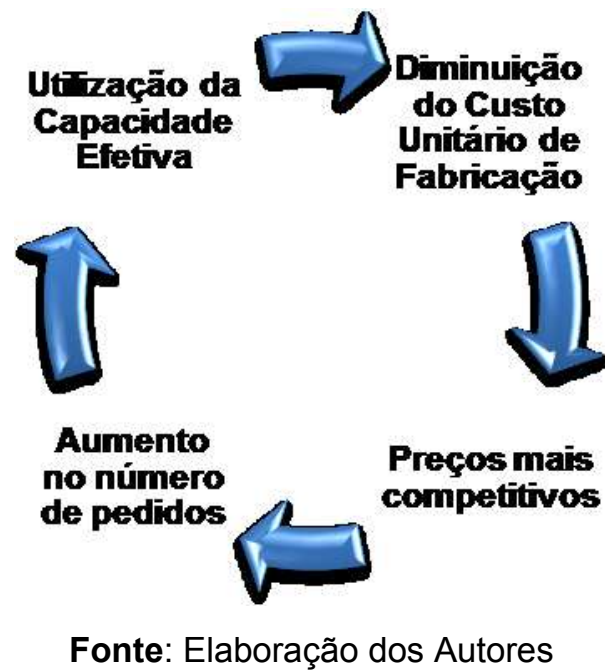

A Figura 3 mostra que ao utilizar a capacidade efetiva, a empresa diminui o custo unitário de fabricação de seus produtos, podendo assim ter preços mais competitivos (já que os custos serão menores), aumentando o número de pedidos, para então utilizar a capacidade efetiva.

\section{CONCLUSÕES}

Os fornecedores ditam o preço das resinas e o variam conforme o preço do barril de petróleo, enquanto os clientes buscam preços cada vez mais baixos de suas embalagens. Portanto, a empresa precisa encontrar estratégias para competir no mercado, que está cercado por indústrias de transformação plástica, que podem ou não personalizar seus pedidos, influenciando diretamente o PPCP, já que este precisará de uma gestão voltada para personalização destes, cumprimento de prazos de entrega e utilização da capacidade instalada, para garantir baixo custo de produção.

Para mensurar o custo de cada produto, foi aplicado o método centro de custos. Após a aplicação, pôde-se perceber que cada produto apresenta suas particularidades e principalmente, destacou o quanto os custos são afetados pela capacidade: ao vender com preços altos, para compensar sua ociosidade, a empresa perde pedidos para a concorrência. 
A empresa tem condições de competir se utilizar a capacidade efetiva. Fato este mostrado nas Tabelas 21, 22 e 23: a diminuição do preço de venda, para garantir a utilização da capacidade efetiva, diminui os custos e aumenta o lucro. Ao conhecer seus custos por centros produtivos a empresa pode aumentar o número de pedidos e sua carteira de clientes, deixando evidente a importância da utilização da capacidade efetiva para diminuição dos custos.

Portanto, o PPCP e a gestão da capacidade mostram-se como elementos fundamentais, aliando-se a gestão de custos para aumentar sua margem por quilo vendido.

Este trabalho aponta como sugestões a elaboração de um planejamento de longo prazo, fazendo uma previsão de demanda acurada com o intuito de garantir a plena utilização de seus recursos. Além da necessidade de um controle de custos contínuo, para atingir custos cada vez mais baixos, com produtos de qualidade e prazos de entrega que possam ser cumpridos, visando à satisfação dos clientes.

\section{REFERÊNCIAS}

BIKFALVI, P.; ERDÉLYI, F.; TÓTH, T. The "Production triangle" model in production planning and control. IEEE International Conference on Automation, Quality and Testing, Robotics AQTR 2010 - THETA 17th edition, Romania, maio 2010.

BONNEY, M. Reflections on Production Planning and Control (PPC). Revista Gestão \& Produção. São Paulo, v.7, n.3, p.181-207, dez. 2000

BORNIA, A.C. Análise gerencial de custos: aplicação em empresas modernas. São Paulo: Atlas, 2009.

BRUNI, A. L.; FAMÁ, R. Gestão de custos e formação de preços: com aplicações na calculadora HP 12C e Excel. 5. ed. São Paulo: Atlas, 2008.

CORRÊA, H.L.; CORRÊA, C.A. Administração de produção e operações manufatura e serviços: uma abordagem estratégica. 2. ed. São Paulo: Atlas, 2007.

CORRÊA, H.L.; GIANESI, I.G.N.; CAON, M. Planejamento, programação e controle da produção. 5. ed. São Paulo: Atlas, 2007.

DUTRA, F.A.; ERDMANN, R.H. Análise do planejamento e controle da produção sob ótica da teoria da complexidade. Revista Produção, v. 17, n. 2, p. 407-419, maio/ago. 2007. 
ELETROBRÁS. Estimativa de consumo médio mensal de eletrodomésticos. Disponível em: <http://www.eletrobras.com.br>. Acesso em: 18 nov. 2011.

FREIRES, F.G. Gerenciamento de custos e riscos. Curitiba: IESDE Brasil, 2011.

HYDNES, M.D. Project and capacity management: an application to drug development. Computers and Cheminal Engineering, v. 33, p. 1994-1998, 2009.

GANTZEL, G.; ALLORA, V. Revolução nos custos. Salvador: Casa da Qualidade, 1996.

JACK, E.P; POWERS, T.L. A review and synthesis of demand management, capacity management and performance in health-care services. International Journal of Management Reviews. v. 11, n. 2 p. 149-174, June 2009.

KUNH, P.D.; FRANCISCO, A.C.; KOVALESKI,J.L. Aplicação e utilização do método unidade de esforço de produção (UEP) para análise gerencial e como ferramenta para o aumento da competitividade. Revista Produção Online. v.11, n. 3, p. 688706, jul./set., 2011.

MARTINS, E. Contabilidade de custos. 9. ed. São Paulo: Atlas, 2008.

LEONE, G.S.G. Curso de contabilidade de custos. 2 ed. São Paulo: Atlas, 2000.

MIGUEL, P. A. C. Estudo de caso na engenharia de produção: estruturação e recomendações para sua conclusão. Produção, 17, n. 1, p. 216-229, 2007.

MOREIRA, D. A. Administração da produção e operações. São Paulo: Pioneira, 2008.

MONTAÑÉS, M.A.J.; GRACIA, S.V.D. El coste de producción de las existencias valorado al nivel de utilización de la capacidad normal. Revista del Instituto Internacional de Costos. v. 8, p. 93-116, enero/junio 2011.

NAKANO, D. Métodos de Pesquisa adotados na engenharia de produção e gestão de operações. In: MIGUEL, P. A. C. Metodologia de pesquisa em engenharia de produção e gestão de operações. Rio de Janeiro: Elsevier, 2010. p. 63-72.

NYHUIS F.; PEREIRA FILHO, N.A. Methods and tools for dynamic capacity planning and control. Revista Gestão \& Produção, v.9, n.3, p. 245-260, dez. 2002.

PACHECO, D.A.J.; ANTUNES JÚNIOR, J.A.V.; LACERDA, D.P.; GOLDMEYER, D.B.; GILSA, C.V. Modelo de Gerenciamento da capacidade produtiva: Integrando Teoria das restrições e o índice de rendimento operacional global (IROG). Revista Produção Online, v.12, n.3, p.806-826, jul./set. 2012. 
REIS, E.C. Modelo de gestão de custos integrado com a contabilidade fiscal em um operador logístico. Dissertação (Mestrado Profissional em Transporte).

Programa de Pós-graduação em Engenharia Civil, Universidade Federal de Santa Catarina, Escola de Engenharia, 2008.

SABBADINI, F.S.; GONÇALVES A. A.; OLIVEIRA, M.J.F. A aplicação da teoria das restrições (toc) e da simulação na gestão da capacidade de atendimento em hospital de emergência. Revista Produção Online. v.6, n.3, p.51-70, set./dez. 2006

SLACK, N., CHAMBERS, S., JONNSTON, R. Administração da produção. 2. ed. São Paulo: Atlas, 2009.

SNEAD, K. STOTT, D. GARCIA, A. The causes of misapplied capacity related manufacturing costs and corresponding reporting implications: A conceptual perpective. Journal of Accounting Education. v. 28, p. 85-102, 2010.

SOARES, H.F. O comportamento da demanda e suas implicações na gestão de operações: um estudo de caso de uma empresa de eletrodomésticos.

Dissertação (Mestrado em Engenharia de Produção). Programa de Pós Graduação em Engenharia de Produção, Universidade Federal de São Carlos, 2006.

STIEG, C.M., ERFURTH, A.E., AVILA, L.V., BRISCHIGLIARI, E. Estudo sobre a apuração de custos numa indústria de molas no sul de Minas Gerais. CONGRESSO BRASILEIRO DE CUSTOS, 18, 2011. Rio de Janeiro. Anais... Rio de Janeiro, 2011.

TUBINO, D.F. Planejamento e controle da produção: teoria e prática. 2 Ed. São Paulo: Atlas, 2009.

VOSS, C.; TSIKRIKTSIS, N.; FROHLICH, M. Case research in operations management. International Journal of Operations \& Production Management, 22, n. 2, 2002. 195-219.

YIN, R. K. Case study research: design and methods. 4. ed. California: Sage Publications, 2009.

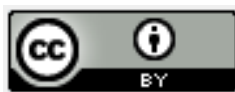

Artigo recebido em 13/02/2012 e aceito para publicação em 03/06/2013 